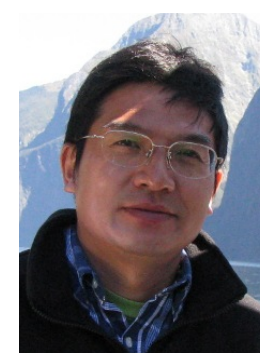

Sam Meng

Institute for Rural Futures, BCSS

University of New England, Australia

\title{
THE CONTRIBUTION OF CARBON PRICING TO SUSTAINABLE
} MINING

\author{
Mahindra Siriwardana \\ UNE Business School \\ University of New England, Australia
}
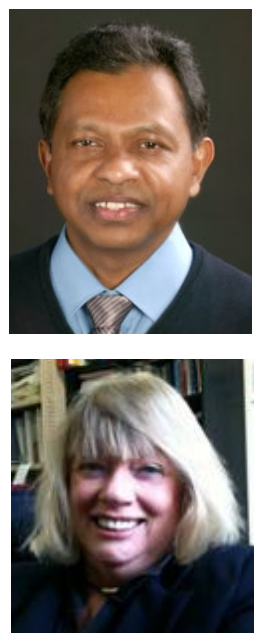

Reductions in greenhouse gas emissions are essential to reducing the rate and scale of anthropogenic climate change to levels that can sustain the planet's biosphere. A carbon tax is a policy measure that is designed to reduce greenhouse gas emissions by increasing the prices of the highest carbon-polluting goods and services in an economy, thus encouraging substitution towards resultant relatively cheaper and less-polluting goods where possible. When Australia introduced such a tax in 2012, there was a fear that it could threaten the resources boom, considered the engine of Australian economic growth in recent years. By employing a computable general equilibrium model and an environmentally-extended Social Accounting Matrix, this paper demonstrates the effects of a carbon tax on the resources sector. The modelled results show that, in a flexible exchange rate regime, all resources within the sector will be affected negatively but to different degrees. The brown coal sector will be the hardest hit, with a 25.74 per cent decrease in output, 52.94 per cent decrease in employment and 89.37 per cent decrease in profitability. However, other resources in the sector would be only mildly affected. From the point of view of sustainability, the most significant results are that, under the carbon tax, the resources sector contributes considerably to the carbon emission reduction target of Australia. Given that brown coal accounts for only a small portion of the resources sector, it is reasonable to suggest that a carbon tax would not significantly affect the overall performance of the sector.

\section{Introduction}

Australia has rich natural resource deposits and its resources sector has long been a key contributor to the Australian economy. In recent years, the strong demand for minerals and energy by emerging economies like China and India has led to an unprecedented increase in investment and production in the Australian resources sector; the so-called Australian resources boom. Even during the Global Financial Crisis (2008-09), the resources sector contributed about $A \$ 160$ billion in export earnings, accounting for over 80 per cent of Australian commodities exports, nearly 70 per cent of total merchandise exports and 56 per cent of total goods and services exports. ${ }^{1}$ The gross value added (GVA) of the resources sector accounted for 25.3 per cent of GVA in Western Australia, 26.5 per cent in the Northern Territory, and 8.3 per cent in Queensland. ${ }^{2}$ According to the Minerals Council of Australia (MCA), in 2009-10, the minerals industry accounted for 8 per cent of national Gross Domestic Product (GDP), and employed 158000 workers directly and 505600 indirectly. ${ }^{3}$ Mining companies paid more than A\$7 billion in royalties as a part of A\$21 billion in state and

\footnotetext{
Australian Bureau of Agricultural and Resource Economics, Australian Commodity Statistics 2009, (ABARE, 2009).

Australian Bureau of Statistics (ABS), Australian National Accounts: Input-Output Tables 2004-05(ABS, catalogue no 5209.0, 2008).

Minerals Council of Australia, The Australian Minerals Industry and the Australian Economy (MCA,

2010)<http://www.minerals.org.au/file_upload/files/publications/Aus_min_industry_fact_sheet_March_2010.pdf>
} 
federal taxes. The resources sector has also made significant contributions to investment and new project development, and to rural and regional development.

When the then Australian Government introduced a carbon tax, effective from 1 July 2012, the measure provoked strong opposition in the resources sector. The MCA claimed that 'the Australian mining industry will pay in the order of $\mathrm{A} \$ 25$ billion in carbon taxes up to 2020'. ' David Peever, the Managing Director of one of the biggest mining companies, Rio Tinto, complained that 'Australia's minerals sector now faces significant additional costs not faced by competitors'. ${ }^{5}$ The Chief Executive of the MCA, Mitch Hooke, claimed that the impact of the carbon tax on the resource sector would be to 'export investment, jobs, global market share, and emissions offshore'. ${ }^{6}$

A carbon tax does indeed increase some production costs. Carbon tax policy is designed to reduce greenhouse gas emissions by increasing the prices of the highest polluting goods and services in an economy, encouraging substitution towards relatively cheaper, less polluting inputs into production processes and towards consumption of less polluting final goods, where possible. On the one hand, increased production costs reduce profit margins and thus discourage investment in the resources sector. Higher production costs lead to higher output prices, thus reducing demand for mining commodities, which in turn reduces output and employment in the resources sector. However, the important empirical question is: are the cost increases to the resources sector arising from a carbon tax significant enough to affect the mining boom? Macroeconomic modelling can be used to answer this question by quantifying the effects of a carbon tax.

The Australian Treasury undertook comprehensive modelling to support the carbon tax policy. A suite of models was employed, including two computable general equilibrium (CGE) models, one input-output model and a number of micro models for the electricity and road transport sectors (the discussion under the third heading of this paper will provide more details on the Treasury modelling). By its nature, this modelling is intricate and complex, and the results depend on the compatibility of the model integration as well as on the parameters and assumptions made (as with all models). Some assumptions may have proved optimistic. For example, the MCA strongly criticised the 'heroic' assumption in the simulation that there will be a global carbon price and international emissions trading in place by 2016.

In this paper we adopt a simpler approach. In the real world, many forces are acting on an economy at any one point in time. It is difficult to disentangle the effects of, for example, the global financial crisis, the resources boom and the new carbon tax. To single out the effects of a carbon tax, we introduce a 'ceteris paribus' assumption regarding all other real world impacts, and construct a single-country, static CGE model (ie, capable of measuring impacts across all industries in the economy at a point in time). We also develop an environmentally-extended micro Social Accounting Matrix (SAM). Based on the simulation results, our research endeavours to uncover the implications of a carbon tax policy for the resources sector.

The balance of the paper is organised as follows. The next section reviews previous studies on the effect of a carbon pricing policy using CGE modelling. The section is followed by one that describes the model structure and database for the simulations, and then we present and discuss the simulation results with special reference to the minerals and energy sectors. The final section summarises the results and provides some comments.

\section{Previous studies}

The effect of a carbon tax is well researched internationally. ${ }^{7}$ For the purposes of this paper we review only studies with an Australian context.

\footnotetext{
${ }^{4}$ Paul Sutherland, 'Mining Industry Says Carbon Tax Will Cost It Billions of Dollars', ABC Rural (online), 9 July 2011<http://www.abc.net.au/site-archive/rural/news/content/201111/s3359828.htm>.

Sarah-Jane Tasker, 'Carbon Price Threat to Mining Sector Jobs', The Australian (Sydney), 11 July 2011.

6 International Centre for Trade and Sustainable Development, 'Australian Government to Tackle Carbon Emissions with Tax on Polluters', 25 July $2011<$ http://ictsd.org/i/news/biores/111179/>.

7 See, eg, L Beausejour et al, 'An Environmental CGE Model of Canada and the United States' (Fiscal Policy and Economic Analysis Branch Working Paper No 92-04, Department of Finance, Ottawa, 1992); K Hamilton and G Cameron, 'Simulating the Distributional Effects of a Canadian Carbon Tax' (1994) 20 Canadian Public Policy 385; Z Zhang, 'MacroEconomic and Sectoral Effects of Carbon Taxes: A General Equilibrium Analysis for China' (1998) 10 Economic Systems Research 135; X Labandeira et al, 'Green Tax Reforms in Spain' (2004) 14 European Environment 290; W Wissema and R Dellink, 'AGE Analysis of the Impact of a Carbon Energy Tax on the Irish Economy' (2007) 61 Ecological Economics 671; S Devarajan et al, 'Tax Policy to Reduce Carbon Emissions in a Distorted Economy: Illustrations from a South Africa CGE Model' (2011) 11 The BE Journal of Economic Analysis and Policy 1.
} 
The Centre of Policy Studies at Monash University (since relocated to Victoria University) in Melbourne, developed the Monash Multi-Regional Forecasting (MMRF)-Green model to address the carbon emissions issue in Australia. Although MMRF-Green is mainly employed in analysing carbon emissions trading, ${ }^{8}$ it is used in the Treasury modelling on carbon taxes, so we briefly discuss it here. MMRF-Green is a dynamic, single country, multi-regional model. The modelling included 52 industry sectors, 56 commodities, and eight states (or 57 sub-states). Each state has a single representative household and a regional government. There is also a federal government. In order to avoid changing the CGE core substantially, the substitution effect between energy inputs and between types of electricity generation are realised through the different sizes of various input-saving technological changes for each commodity. This is a convenient alternative expression of the substitution effect but is only workable in a dynamic model and in the long run. In a static simulation, which is used here, technology is assumed unchanged and all these substitution effects will disappear. There are five emission activities: four cover emissions from combustion of black coal, brown coal, natural gas and petroleum products; and one covers emissions from fugitive and non-combustion sources. The emissions data were obtained from the National Greenhouse Gas Inventory (NGGI) summary report by the Australian Government.

To accompany the carbon tax in Australia, the Treasury carried out an ambitious and complex, large-scale carbon price modelling. It consisted of a number of models including the Global Trade and Environment Model GTEM model, which provided the international economic and emissions context for modelling of the Australian economy, and the MMRF model, which projected the national, regional and sectoral impact of carbon taxes. With the world carbon price paths being set, the model for the assessment of greenhousegas-induced climate change (MAGICC) was used to estimate the greenhouse gas atmospheric concentration levels. The ROAM Consulting (ROAM) model and the Sinclair Knight Merz (SKM MMA) model were used to provide detailed bottom-up information of the Australian electricity generation sector. The Energy sector model (ESM) by the Commonwealth Scientific and Industrial Research Organisation (CSIRO) was used to model the road transport sector. The price revenue incidence simulation model and distribution model (PRISMOD.DIST) were used to examine the distributional implications of carbon pricing for households. The modelling framework and results were included in the Treasury report: Strong Growth, Low Pollution Modelling a Carbon Price. ${ }^{9}$

Overall, the Treasury modelling results, with two starting carbon prices in 2012-13 (A\$20 and $A \$ 30)$, show quite positive effects: the economy continues to grow strongly and carbon emissions are reduced substantially. It was projected that, without a carbon tax, Australian Gross National Income (GNI) per person by 2050 would be around 60 per cent higher and emissions 74 per cent higher than they are today. With a carbon price in place, the difference in GNI is not dramatic: GNI per person would be at least 56 per cent higher, yet emissions would fall by 80 per cent. In the core policy scenario (starting carbon price in 2012-13 at $\mathrm{A} \$ 20$ ), around 1.6 million jobs are projected to be created to 2020 and a further 4.4 million to 2050; average weekly household expenditure was projected to be about $\$ 9.90$ higher in $2012-13$, of which electricity accounts for around $\$ 3.30$ and gas around $\$ 1.50$. However, the Treasury modelling may have limitations. The accuracy of such results is not only subject to the degree to which integration of the various models could be achieved effectively, but projections so far into the future must be subject to the usual precautionary caveats.

\section{Model structure and database}

Because the purpose of this study is to assess the effect of a carbon tax in the short run, instead of forecasting the performance of the economy into the future under a tax, the model developed for this study is a static CGE model based on ORANI-G. ${ }^{10}$ The comparative static nature of ORANI-G helps to single out the influence of a carbon tax by holding all other influences constant. The model employs standard neoclassical economic assumptions: a perfectly competitive economy with constant returns to scale, cost minimisation for industries and utility maximisation for households, and continuous market clearance. In addition, zero profit conditions are assumed for all industries because of perfect competition in the economy. For those

\footnotetext{
8 See, eg, Allen Consulting Group, 'Greenhouse Emissions Trading' (Report to the Victorian Department of Premier and Cabinet, Melbourne, 2000); P Adams, 'Insurance Against Catastrophic Climate Change: How Much Will an Emissions Trading Scheme Cost Australia?’ (2007) 40 Australian Economic Review 432.

9 The Treasury, 'Strong Growth, Low Pollution - Modelling a Carbon Price' (Commonwealth of Australia, Canberra 2011).

${ }^{10}$ Mark Horridge, ‘ORANI-G: A General Equilibrium Model of the Australian Economy' (Centre of Policy Studies and IMPACT Project Preliminary Working Paper OP-93, Monash University, 2000).
} 
less familiar with modelling, these assumptions are standard practice and necessary for the model to 'solve' economy-wide.

The Australian economy is represented by 35 sectors that produce 35 goods and services, one representative investor, ten household groups, one government and nine occupation groups. Final demand comes from households, investment, government and exports. With the exception of the production function, which we have specified in more detail below, we have adopted the functions used in the multi-households version of ORANI-G.

Overall, the production function is a five-layer nested Leontief-CES function. As in the ORANI model, the top level is a Leontief function describing the demand for intermediate inputs and composite primary factors, and the remainder are various CES functions at lower levels. However, the treatment with energy inputs is very different from the ORANI model.

Energy inputs are treated differently in this model because most are emissions intensive and, thus, essential to a model concerned with the impact of a carbon tax. We argue that energy efficiency is positively related to investment in energy-saving devices; for example, well-insulated housing uses less energy for airconditioning. We, therefore, assume that there are some possibilities for substitution between energy goods and capital. We also assume that the size of the substitution effect depends on the cost and the availability of energy-saving technology, which is reflected in the value of the substitution elasticity. Technically, these substitution possibilities are defined as follows. At the first level, Constant Elasticity of Substitution (CES) functions are used to combine black coal, brown coal, and oil and gas, to form 'composite coal, oil and gas' whilst automobile petrol, kerosene, LPG and other petrol combine to form 'composite petroleum'. At the second level, composite coal, oil and gas, petroleum and commercial electricity are combined by a CES function to form 'composite energy'. At the third level, a CES function is used to combine composite energy and capital to form the capital-energy composition. At the fourth level, a CES function is used to combine the capital-energy composition, and the factors labour and land to form the primary factor composite. At the fifth level, the primary factor, electricity generation and general intermediate inputs are combined by a Leontief function to create sector output. Our treatment of energy inputs is similar to that used by other researchers focussing on carbon emissions. ${ }^{11}$

The functions for final demands are similar to those in the ORANI model. ${ }^{12}$ For example, the investment demand is a nested Leontief-CES function, and the household demand function is a nested LES-CES function. Export demand is dependent on the price of domestic goods, and government demand follows household consumption. However, unlike the assumption in ORANI of exogenous either total or supernumerary household consumption, we assume that total consumption is proportional to total income for each household group.

The main data used for the modelling include input-output data, carbon emission data, and various behavioural parameters. The input-output (I-O) data used in this study are from the Australian Input-Output Tables 2004-2005. ${ }^{13}$ There are 109 sectors (and commodities) in the original I-O tables. For the purpose of this study, we disaggregate the resources sectors and aggregate other sectors to form 35 sectors (and therefore 35 commodities). Utilising data from the household expenditure survey, ${ }^{14}$ the household income and consumption data were disaggregated to ten household groups according to income level, while labour supply was disaggregated to nine occupation groups.

\section{Simulation analysis}

The purpose of this study is to gauge the impact of a carbon tax on the resources industry, so the level of carbon tax is chosen to reflect the actual Australian tax, namely, \$23 per tonne of carbon emissions, exempting the agriculture, road transport and household sectors. In the Australian policy, government compensation for the tax was quite complicated. There were various levels of compensation to a number of

\footnotetext{
${ }^{11}$ See, eg, J Burniaux et al, 'GREEN a Multi-Sector, Multi-Region General Equilibrium Model for Quantifying the Costs of Curbing CO2 Emissions: A Technical Manual’ (OECD Economics Department Working Papers No 116,0ECD Publishing, 1992), doi:10.1787/744101452772; H Ahammad and R Mi, 'Land Use Change Modelling in GTEM - Accounting for Forest Sinks' (ABARE Conference Paper 05.13, Canberra, 2005); S Devarajan et al, 'Tax Policy to Reduce Carbon Emissions in South Africa' (Policy Research Working Paper WPS4933, The World Bank, Africa Region, 2009); Zhang, above n 7.

12 Peter B Dixon et al, ORANI: Multisectoral Model of the Australian Economy (North-Holland, 1982).

${ }^{13}$ ABS, above $n 2$.

${ }^{14}$ Australian Bureau of Statistics (ABS), Household Expenditure Survey Australia 2004-05 (ABS catalogue no 6530.0, 2006).
} 
manufacturing and exporting industries. For households, the then government changed tax thresholds and initiated various family tax benefits, such as a clean energy advance, clean energy supplement and a single income family supplement. ${ }^{15}$ In order not to complicate the study unduly, we approximated these measures by imposing simple revenue-neutral compensation for households: all carbon tax revenue is transferred in lump sum to the six poorest household deciles.

Two scenarios are simulated and compared in this study: (A) Carbon tax only, and (B) Carbon tax plus household compensation. The study is mainly concerned with short-run effects, so a short-run macroeconomic closure of the model is assumed; for example, fixed real wages and capital stocks, free movement of labour but immobile capital between sectors. Government expenditure follows household consumption. The exchange rate is set as endogenous to reflect the flexible exchange regime in Australia. In doing so, the Consumer Price Index (CPI) had to be set as exogenous. Since the focus of this study is on the resources sector, the results on other sectors are aggregated and listed as a comparison. Unless specified, all projections reported in this paper are shown in percentage changes.

\section{Macroeconomic and environmental results}

Firstly, we consider the macroeconomic results, as shown in Table 1. The modelling results show that under both scenarios, carbon emission cuts would be significant but the economy slows only marginally.

The first panel in Table 1 shows the changes in carbon emission under the two scenarios. The results show that a $\$ 23$ per tonne carbon tax is quite effective - it reduces carbon emissions by 70.364 mega tonnes, or almost 12 per cent of the emission base. In scenario B (with compensation to households), emission cuts are less than in scenario (A) Carbon-tax-only. This is because the transfer of money to households would encourage consumption of goods of all kinds, including emission-intensive goods. As a result, carbon emissions will be greater compared with the no-compensation scenario. However, the difference between the two scenarios is fairly small: 0.101 megatons or 0.017 per cent of the emission base. The small difference may indicate that the household consumption pattern changes under a carbon tax. Households will consume less emission-intensive goods and more of other goods, motivated by the price rise in emission intensive goods.

Table 1 Macroeconomic environment

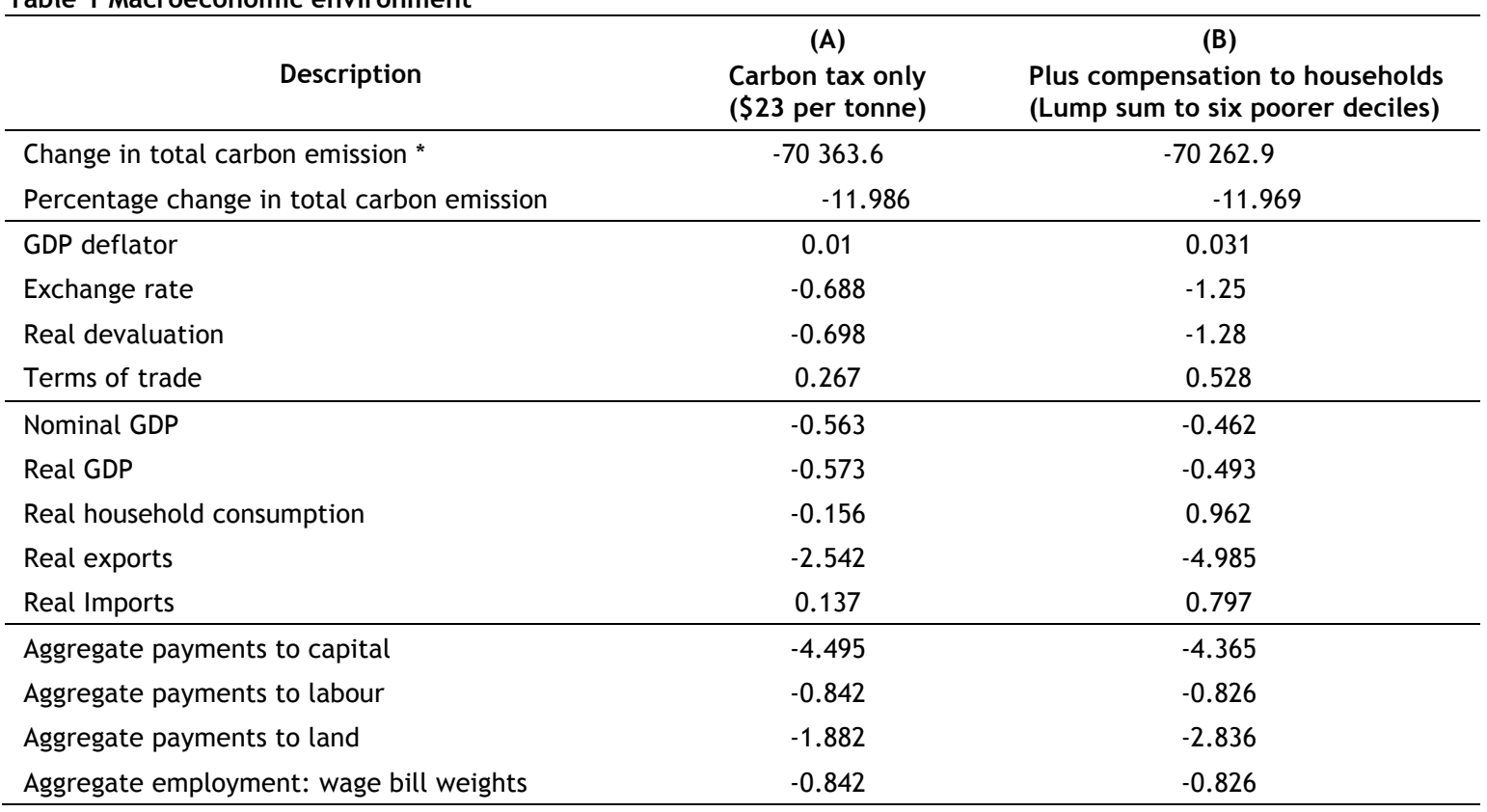

*Nominal change in kilo tonnes.

The second panel shows the changes in the price level. Since the CPI is unchanged under the flexible exchange rate assumption of the modelling, the GDP price index (GDP deflator) acts as the indicator of price levels in the economy. The simulation results show that price increases are only slight (by $0.01 \%$ in scenario $A$ and $0.03 \%$ in scenario (B)). This is not the whole story, however, as under the flexible exchange rate

\footnotetext{
${ }^{15}$ Clean Energy Act 2011 (Cth).
} 
regime the upward pressure on price levels is also reflected in a more expensive Australian dollar - the exchange rate (local currency/foreign currency) decreases by 0.688 per cent in scenario A. With the 0.01 per cent increase in the GDP price index and a 0.688 per cent appreciation of Australian currency, the Australian dollar is inflated overall by $0.01+0.688=0.698$ per cent. Given unchanged world prices, this appreciation of the Australian dollar makes imports cheaper for Australians. At the same time, it discourages export demand (because of the higher prices faced by foreigners), which leads to a decrease in export prices denominated in local currency. Since the decrease in the price of exports is less than that of imports, Australia's terms of trade improves by 0.267 per cent.

The third panel displays the changes in GDP and its components on the expenditure side. The decrease in real GDP is to be expected because a carbon tax increases production costs and thus discourages commodity supply. In scenario B, real GDP declines comparatively less because the compensation policy stimulates household consumption, which will induce a higher equilibrium output than in scenario $\mathrm{A}$. In both scenarios, nominal GDP decreases slightly less than real GDP. This is because of the marginal increase in the GDP deflator. Household consumption decreases in scenario A due to the lower income resulting from the scaling back of production in the economy, but it increases significantly in scenario B, apparently due to the increase in household income arising from the government's lump sum compensation. The decrease in exports and increase in imports are the immediate effects of the appreciation of the Australian dollar: the more expensive Australian dollar meaning higher prices of Australian exports faced by foreigners and cheaper imports for Australians. The greater changes in imports and exports in scenario B compared with scenario (A) are consistent with the further appreciation of the Australian dollar under the household compensation package.

The last panel shows the changes in aggregate employment and in aggregate payments to factors of production. Payments to capital decrease considerably under both scenarios. This decrease may stem from the fact that the decrease in demand for capital exerts downward pressure on the capital rental price. Improved aggregate payments to capital in scenario B are consistent with the improved GDP and household consumption in this scenario. Aggregate payments to labour decrease significantly in scenario A, but improve slightly in scenario $B$. This result agrees with the negative movements in GDP in both scenarios and the smaller GDP change in scenario B. Aggregate employment declines at the same pace as aggregate payments to labour. This can be explained by the assumptions used in the simulation: the real wage is assumed unchanged in the short run and the nominal wage is fully indexed with the CPI, which is fixed under the flexible exchange rate regime. Aggregate payments to land decrease less than the aggregate payments to capital. This is because land is mainly used by the agricultural sector, which is less affected by the carbon tax because of the exemption of this sector from the tax.

\section{Sectoral performance}

In this section we discuss the impact of a carbon tax on the resources sector through sectoral output, employment and profitability, as shown in Table 2. For comparison, the other sectors are aggregated and shown in the last row of the table.

The output change of the brown coal sector is substantial - more than a 25 per cent decrease in both scenarios. This indicates that the brown coal industry would be expected to be under substantial pressure following a carbon tax. Although the sector would be unlikely to become financially unviable in the shortrun, it may begin to phase out over time. For other resources, the impact of a carbon price is very mild; output changes for them are very small. Given that brown coal production is only a very small portion of total energy resources and Victorian coal-fired electricity generators are the main purchasers of brown coal in Australia, it not surprising that the overall effect of a carbon tax on the resources sector appears to be mild. The magnitude of output changes in 'The other sectors' category is similar to that of the black coal sector, which is larger than those in each of the oil, gas, and minerals sectors. The more significant output decreases in 'The other sectors' category may be attributed to the presence of some energy-intensive sectors in that broad category. For example, while the impact of a carbon tax on the service sectors should be very marginal due to their low emission contribution, the impact on some manufacturing sectors, such as oil refining, chemical production, steel and aluminium manufacturing, would be large due to their high energy usage and high activity emissions base. The largest impact within 'The other sectors' category would be in the electricity sectors, because those sectors produce large amounts of stationary carbon emissions. 
Table 2 Sectoral output, employment and profitability

\begin{tabular}{lcccccc}
\hline \multirow{2}{*}{ Sectors } & \multicolumn{3}{c}{ Output } & \multicolumn{2}{c}{ Employment } & \multicolumn{2}{c}{ Profitability } \\
\cline { 2 - 7 } & $\begin{array}{c}\text { (A) Carbon } \\
\text { tax only }\end{array}$ & $\begin{array}{c}\text { (B) Tax plus com- } \\
\text { pensation }\end{array}$ & $\begin{array}{c}\text { (A) Carbon } \\
\text { tax only }\end{array}$ & $\begin{array}{c}\text { (B) Tax plus com- } \\
\text { pensation }\end{array}$ & $\begin{array}{c}\text { (A) Carbon } \\
\text { tax only }\end{array}$ & $\begin{array}{c}\text { (B) Tax plus com- } \\
\text { pensation }\end{array}$ \\
\hline Black coal & -0.764 & -0.847 & -2.843 & -3.215 & -7.272 & -7.928 \\
Brown coal & -25.744 & -25.656 & -52.941 & -52.895 & -89.367 & -89.326 \\
Oil & -0.107 & -0.136 & -0.926 & -1.234 & -1.858 & -2.353 \\
Gas & -0.402 & -0.415 & -2.734 & -2.987 & -7.423 & -7.799 \\
Minerals & -0.414 & -0.545 & -1.23 & -1.725 & -3.422 & -4.354 \\
The other & -0.742 & -0.733 & -0.808 & -0.769 & -4.191 & -3.792 \\
sectors & & & & &
\end{tabular}

The changes in employment are shown in the fourth and fifth columns of Table 2 . They have the same sign as the changes in output, but the magnitude of change is much larger. The bigger change in employment may be related to the short-run assumptions used in the simulations. The constant return to scale assumption indicates that the output level changes at the same pace as the changes in all inputs. However, capital is assumed fixed in the short run, so the labour input has to change at a greater extent than does output. For the resources sector, the difference between the change in employment and the change in output is much greater. It is surprising to find that, while the output of the brown coal sector decreases by about 25 per cent, employment decreases in this sector by more than 52 per cent. This may indicate that, compared with the other sectors, the brown coal sector is relatively labour-intensive. These results remind us that a carbon tax may have significant implications for employment and thus governments should consider appropriate social policies (for example, structural adjustment assistance) to cope with a large amount of unemployment in sectors like brown coal, if jobs are not on offer elsewhere in the sector.

The changes in profitability in the last two columns of Table 2 have the same signs as output and employment, but the percentages are higher. The profitability of the brown coal sector decreases by nearly 90 per cent. This volatile profitability is the result of a dramatic shrinking of the profit margin due to the squeeze from both the demand side and the supply side: the decrease in demand leads to the decrease in output prices while the carbon tax leads to a significant increase in production cost. However, profitability decline may also come from the short-run assumption of immobility of capital. That is, it is assumed that capital is immobile in the short run and thus is fixed for each sector. The assumption implies that changes in demand for capital, which are induced by changes in demand for sectoral outputs, have to be transferred exclusively to the changes in the capital rental price, a core component of profitability.

\section{Conclusions}

In this study, we constructed a CGE model with an environmentally-extended micro Social Accounting Matrix and simulated the effect of a \$23 per tonne carbon tax in Australia. The main economic question we sought to investigate was whether the cost increases arising from a carbon tax would have a significant effect, as many feared, on the minerals and energy sector and, therefore, on Australia's resources boom. The modelling indicates that the impact on the macro economy would be mild. Under a carbon tax only scenario (ie, without household compensation) the tax causes a 0.57 per cent decrease in real GDP, a 0.16 per cent decrease in real household consumption and a 0.84 per cent decrease in employment. The overall price level indicated by the GDP deflator increases by 0.01 per cent while the Australian dollar appreciates by 0.69 per cent. Under the carbon tax plus household compensation scenario, real GDP, household consumption and terms of trade improve significantly relative to the carbon tax only scenario, but the price level (indicated by both the GDP deflator and the exchange rate) increases further and employment deteriorates slightly.

The impact of the carbon tax on the minerals and energy sector as a whole is negative but varies across commodities. Not surprisingly, the brown coal sector is the worst affected, with a 25.74 per cent decrease in output, a 52.94 per cent decrease in employment and an 89.37 per cent decrease in returns to capital. A lesson to be learned from this is that governments must be prepared to implement appropriate structural adjustment policies, if alternative employment is not available. The impact on other resources sectors is relatively mild: 0.11 per cent to 0.76 per cent decrease in output; 0.93 per cent to 2.84 per cent decrease 
in employment; and 1.86 per cent to 7.42 per cent decrease in profitability. Given the fact that brown coal accounts only for a small portion of the resources sector, it is reasonable to suggest that a carbon tax would not significantly influence the overall performance of the sector.

From a sustainability point of view, the most significant results are that a carbon tax of $\$ 23$ per tonne can cut carbon emissions effectively (by 70.3 megatons or $12 \%$ of the emission base in our modelling). This is indeed what has happened in Australia, although perhaps to a lesser extent than is indicated in the simulations. Other factors are always at play, but Australian emissions in the electricity sector, the largest contributor to overall emissions, declined by 8.2 per cent in the two years of operation of the tax, compared to the two previous years. ${ }^{16}$ Emissions for the Australian economy as a whole have also declined slightly overall, despite increases in 'fugitive' emissions (eg, from extraction of natural gas) and increases in the agriculture sector. ${ }^{17}$

The success of the carbon tax (in conjunction with other policy measures) in reducing emissions, in shifting resources to less emissions-intensive sectors, and in providing revenue to support renewable sources of energy, is a good example of policy that is consistent with sustainability principles. The reductions in greenhouse gas emissions are essential if the rate and scale of anthropogenic climate change is to be brought to levels that can sustain the planet's biosphere. Not only this, but on the principle, put simply, that sustainability requires that depletion of natural capital such as minerals be offset by a compensating investment in other forms of capital, ${ }^{18}$ then in economic terms, carbon pricing policy collects some of the rents from an industry that consumes natural capital and reinvests it in other forms of productive capacity.

A new Australian Government repealed the Australian carbon tax in July 2014. A policy based on 'Direct Action' is to replace the carbon tax, although many details of that policy have not yet been explained.

\footnotetext{
${ }^{16}$ Marianna O'Gorman and Frank Jotzo, Impact of the Carbon Price on Australia's Electricity Demand, Supply and Emissions, Australian National University Crawford School of Public Policy, CCEP Working Paper 1411, 17 July 2014) <https://ccep.crawford.anu.edu.au/sites/default/files/publication/ccep_crawford_anu_edu_au/2014-07/ccep1411.pdf>

${ }^{17}$ Australian Government Department of the Environment, Quarterly Update of Australia's National Greenhouse Gas Inventory: December 2013 (Commonwealth of Australia, 2014).

${ }^{18}$ See J M Hartwick, 'Intergenerational Equity and the Investing of Rents from Exhaustible Resources' (1977) 67 American Economic Review 972; Robert M Solow, ‘On the Intergenerational Allocation of Natural Resources' (1986) 88 Scandinavian Journal of Economics 141.
} 